\title{
Soluble CD163 Measurement
}

National Cancer Institute

\section{Source}

National Cancer Institute. Soluble CD163 Measurement. NCI Thesaurus. Code C154728.

The determination of the amount of soluble CD163 present in a sample. 